\title{
PERAN CITRA MEREK MEMEDIASI PENGARUH E-WOM TERHADAP NIAT BELI (Studi Kasus pada Maskapai Penerbangan AirAsia di Kota Denpasar)
}

\author{
Ni Putu Ayu Kartika Kurnia Putri ${ }^{1}$ \\ Tjokorda Gde Raka Sukawati ${ }^{2}$ \\ ${ }^{1,2}$ Fakultas Ekonomi dan Bisnis Universitas Udayana (Unud), Bali, Indonesia \\ email: akartika52@gmail.com
}

\begin{abstract}
ABSTRAK
Tujuan penelitian ini adalah untuk menjelaskan pengaruh $e$-WOM terhadap citra merek, $e$ WOM terhadap niat beli, citra merek terhadap niat beli, serta peran citra merek dalam memediasi pengaruh e-WOM terhadap niat beli. Penelitian ini dilakukan pada konsumen yang berniat menggunakan jasa maskapai penerbangan AirAsia yang berdomisili di Kota Denpasar. Jumlah sampel penelitian ini adalah sebanyak 110 responden dengan menggunakan purposive sampling. Data dikumpulkan dengan menyebarkan kuesioner yang menggunakan skala Likert untuk mengukur 11 indikator. Teknik analisis yang digunakan dalam penelitian ini adalah analisis jalur (path analysis), uji sobel, dan uji VAF. Hasil penelitian ini menunjukkan bahwa variabel $e$-WOM berpengaruh positif dan signifikan terhadap citra merek. Penelitian ini juga menemukan bahwa masing-masing variabel $e$ WOM dan citra merek secara signifikan berpengaruh positif terhadap niat beli. Selain itu, variabel citra merek juga mampu memediasi pengaruh $e-W O M$ terhadap niat beli secara parsial.

Kata Kunci: citra merek, e-WOM, dan niat beli.
\end{abstract}

\begin{abstract}
The purpose of this study was to explain the effect of e-WOM on brand image, e-WOM on purchase intention, brand image on purchase intention, and the role of brand image in mediating the influence of e-WOM on purchase intention. This research was conducted on consumers who intend to use the services of AirAsia airlines domiciled in the city of Denpasar. The number of samples of this study were 110 respondents using purposive sampling. The data were collected by distributing questionnaires using a Likert scale to measure 11 indicators. The analysis techniques used in this study are path analysis (path analysis), sobel test, and VAF test. The results of this study indicate that the e-WOM variable has a positive and significant effect on brand image. This study also found that each e-WOM variable and brand image had a significant positive effect on purchase intention. In addition, the brand image variable is also able to mediate the influence of eWOM on purchase intentions partially. Keywords: brand image, e-WOM, and purchase intention.

Keywords: brand image, e-WOM, and purchase intention
\end{abstract}




\section{PENDAHULUAN}

Transportasi menjadi hal yang sangat penting dalam perpindahan manusia dari suatu wilayah ke wilayah lainnya (Azmarani, 2016). Transportasi adalah pemindahan manusia atau barang dengan menggunakan wahana yang digerakkan oleh tenaga manusia atau mesin. Transportasi digunakan untuk memudahkan manusia untuk melakukan aktivitas sehari-hari (Andriansyah, 2015:1). Transportasi dapat dibedakan berdasarkan tenaga gerak yang dipakai, alat angkutan yang digunakan, serta permukaan jalan yang dipilih menjadi tiga jenis, yaitu transportasi darat, air, dan udara (Kadir, 2006). Salah satu pilihan transportasi yang efektif digunakan untuk menjangkau jarak suatu wilayah yang jauh dengan efisiensi waktu adalah transportasi udara. Transportasi udara adalah transportasi yang memiliki keunggulan mampu menjangkau suatu wilayah yang secara geografis sulit untuk dijangkau dengan waktu tempuh yang relatif lebih cepat dibanding transportasi darat dan transportasi laut (Shulfi dan Syahnur, 2017). Menurut Setiani (2015), transportasi udara mampu bergerak lebih cepat karena mempunyai lintasan yang lurus serta bebas hambatan sehingga menjadi sangat praktis untuk digunakan. Keunggulan transportasi udara tentunya mempunyai manfaat yang positif bagi masyarakat Indonesia dan membuat jasa transportasi udara semakin diminati.

UU No. 1 Tahun 2009 Pasal 97 menjelaskan bahwa angkutan udara niaga berjadwal memiliki tiga jenis pelayanan, diantaranya yang pertama full service atau pelayanan dengan standar maksimum, kedua medium service atau pelayanan dengan standar menengah, dan yang ketiga Low Cost Carrier (LCC) atau 
Ni Putu Ayu Kartika Kurnia Putri, Peran Citra Merek....

pelayanan dengan standar minimum (no frills). Penerbangan berbiaya rendah atau dikenal dengan istilah Low Cost Carrier (LCC) merupakan penerbangan yang memiliki ciri utama harga tiket yang terjangkau dengan pelayanan yang minimalis (Rizki, 2013). Pelayanan minimalis yang dimaksud adalah pelayanan dengan standar minimum (no frills). Layanan no frills atau pelayanan tanpa embel-embel ditujukan untuk penumpang pesawat yang hanya ingin terbang dan sampai di tempat tujuan dengan selamat tanpa embel-embel tambahan seperti layanan makanan dan minuman gratis. Menurut Rizan dkk. (2016) salah satu penerbangan $L C C$ yang sudah mempunyai nama besar baik di dalam maupun luar negeri adalah maskapai penerbangan AirAsia.

Citra positif AirAsia di dunia penerbangan Internasioanl serta keunggulan dalam memberikan harga murah dan promo-promo yang menarik baik untuk rute domestik maupun internasional sangatlah menarik minat masyarakat untuk memilih AirAsia sebagai sarana transportasi udaranya. Hal ini terbukti dengan peningkatan posisi dan Top Brand Index (TBI) AirAsia dalam kategori transportasi udara pada Top Brand Award Indonesia periode 2012 sampai 2014. Tragedi jatuhnya Pesawat AirAsia QZ8501 rute Surabaya - Singapore di Selat Karimata pada tanggal 28 Desember 2014 setelah lepas kontak dari Bandara Djuanda Surabaya menjadi coretan besar dalam sejarah penerbangan AirAsia di Indonesia (Rizan dkk., 2016). AirAsia mengalami penurunan persentase TBI dan posisi secara perlahan-lahan. Menurut portal lengkap dunia marketing (2015), $P R$ AirAsia patut dicontoh karena memiliki respon cepat, bersedia meminta maaf dan bersifat profesional, membuat pembaruan informasi yang kontinyu, bertanggung 
jawab, serta terjun langsung menghadapi keluarga korban. Usaha yang dilakukan AirAsia tentunya juga untuk menjaga pangsa pasarnya di Indonesia, baik pangsa pasar penerbangan domestik maupun penerbangan internasionalnya.

Peneliti melakukan pra survei terhadap 35 responden di Kota Denpasar. Berdasarkan hasil pra survei yang dilakukan pada 35 responden tersebut, dapat dijelaskan bahwa 25 responden belum pernah menggunakan jasa penerbangan AirAsia dan 10 responden sudah pernah menggunakan jasa penerbangan AirAsia sehingga tidak dapat melanjutkan menjawab pertanyaan. Berdasarkan hasil pra survei yang peneliti lakukan, peneliti tertarik untuk menghubungkan variabel $e$ WOM, citra merek, dan niat beli dengan fenomena perkembangan AirAsia. CEO AirAsia di Indonesia menyatakan bahwa "Di era digital dengan media sosial dimana-mana, ketidakbahagiaan satu orang akan menyebar secara luas” (Majalah Marketing GlobeAsia, 2018). Mengacu pada pernyataan tersebut, saat AirAsia tidak berhasil membuat bahagia satu penumpangnya, maka AirAsia tidak hanya kehilangan satu penumpang tersebut untuk melakukan niat beli ulang, melainkan akan kehilangan semua orang yang ada disekitar penumpang tersebut yang memiliki niat beli terhadap AirAsia. Hal ini membuat AirAsia harus memastikan penumpangnya selalu merasa puas dan bahagia sehingga niat beli konsumen lain semakin meningkat.

Niat beli menjadi poin penting bagi pemasar, sebab niat adalah tahap awal yang ikut menentukan apakah individu atau calon konsumen akan memutuskan untuk menggunakan layanan jasa atau produk tertentu (Randi dan Heryanto, 2016). Mahendrayasa dkk. (2014) menjelaskan bahwa niat sebagai dorongan, 
dimana dorongan ini berasal dari dalam individu berupa stimulus yang positif terhadap produk, sehingga dapat memberikan motivasi dalam bertindak. Kemajuan teknologi telah merubah cara masyarakat dalam melakukan interaksi sosial. Dewasa ini, interaksi antar konsumen sudah mengalami perubahan akibat teknologi yang berkembang semakin pesat. Menurut Eriza (2017) teknologi internet memberikan manfaat bagi konsumen dalam sharing informasi, opini, serta saran mengenai pengalaman konsumsi secara online atau yang sering disebut electronic word of mouth (e-WOM).

Secara umum, komunikasi e-WOM merupakan perkembangan dari komunikasi word of mouth (WOM) sebagai dampak keberadaan internet. Jalilvand and Samiei (2012) menyatakan bahwa e-WOM menjadi sebuah "venue" atau sebuah tempat yang sangat penting untuk konsumen memberikan opininya dan dianggap lebih efektif dibandingkan WOM offline karena tingkat aksesibilitas dan jangkauannya yang lebih luas. Penelitian terdahulu yang dilakukan oleh Jalilvand and Samiei (2012), Elseidi and El-Baz (2016), serta Luong et al. (2016) menjelaskan terdapat pengaruh yang positif dan signifikan antara $e-W O M$ dengan niat beli. Kondisi serupa juga dibuktikan dalam beberapa penelitian terdahulu yang menunjukkan pengaruh yang postif dan signifikan antara $e$-WOM dengan niat beli (Anggitasari dan Wijaya, 2016; Iswara dan Jatra, 2017; Ardana dan Rastini, 2018; Darmawan dan Nurcaya, 2018). Dibalik persamaan hasil penelitian yang telah dilakukan tersebut terdapat hasil penelitian yang berbeda, dimana $e$ WOM tidak memiliki pengaruh terhadap niat beli. Torlak et al. (2014) dalam penelitiannya menunjukkan $e$-WOM tidak berpengaruh positif pada niat beli. Hasil 
penelitian yang sama juga dikemukakan oleh Majid dan Rofiq (2014), dimana eWOM tidak memiliki pengaruh terhadap niat beli smarthphone Samsung di Kota Malang.

Berdasarkan reaserch gap yang ditemukan antara variabel $e$-WOM dengan niat beli, diduga ada variabel yang dapat memperkuat hubungan kedua variabel tersebut. Peneliti menambahkan variabel citra merek sebagai variabel mediasi antara $e-W O M$ dengan niat beli. Alasan memasukkan variabel citra merek sebagai variabel mediasi adalah semakin baik citra merek yang tercipta akibat penyebaran e-WOM yang bagus dapat mendorong munculnya niat beli konsumen terhadap suatu produk. Hal ini didukung melalui penelitian sebelumnya yang dilakukan oleh Suyoga dan Santika (2018) yang menunjukkan citra merek berpengaruh postif dan signifikan terhadap niat beli dan mampu memediasi pengaruh $e-W O M$ terhadap niat beli. Jalilvand and Samiei (2012) serta Putra dan Pramudana (2018) menemukan bahwa citra merek memediasi secara parsial hubungan antara $e-W O M$ dengan niat beli.

Penelitian empiris yang telah dilakukan sebelumnya menunjukkan bahwa citra merek menjadi salah satu faktor yang dapat menjembatani pengaruh $e-W O M$ pada niat beli. E-WOM bisa menjadi salah satu faktor timbulnya citra merek melalui informasi atau pendapat yang dibagikan oleh orang lain mengenai merek tertentu (Semuel dan Lianto, 2014). Baik atau buruknya citra merek dari suatu produk akan sangat tergantung pada jenis informasi yang disebarkan oleh konsumen, dimana informasi yang dibagikan mungkin bersifat positif ataupun negatif. Fahrian dkk. (2015), menjelaskan bahwa citra merek adalah cara pandang 
konsumen pada sebuah merek tertentu, dimana cara pandang tersebut berasal dari pertimbangan dan juga persepsi mengenai sebuah merek. Menurut Moksaoka dan Rahyuda (2016), menjelaskan citra merek mampu meningkatkan niat beli konsumen akan sebuah produk karena citra merek dapat menjadi jaminan sehingga konsumen tidak merasa khawatir lagi terhadap merek tersebut. Penelitian terdahulu yang dilakukan oleh Charo et al. (2015); Pratama et al. (2017); dan Indra (2018) menunjukkan variabel citra merek berpengaruh positif signifikan terhadap variabel niat beli. Meskipun demikian terdapat penelitian yang menunjukkan citra merek tidak berpengaruh pada niat beli (Jotopurnomo dkk., 2015).

Perilaku konsumen dapat diprediksi melalui niat membeli, dimana apabila niat beli konsumen tinggi maka kemungkinan konsumen akan membeli produk juga semakin tinggi (Suprapti, 2010: 148). Niat beli dapat diartikan sebagai kondisi psikologis konsumen yang dapat mendorongnya untuk melakukan pembelian karena timbulnya perhatian tinggi akan suatu produk tertentu (Panggalih dan Baridwan, 2013). Niat beli adalah tahapan dimana konsumen melakukan pengevaluasian terhadap informasi yang diterima, hal ini juga berarti bahwa niat beli konsumen adalah apa yang dipikirkan oleh konsumen untuk dibeli (Rismawan dan Purnami, 2017). Prabhawedasattya dan Yasa (2014) menyatakan dalam menganalisis perilaku konsumen, niat beli menjadi salah satu indikator yang sering digunakan. Munculnya niat beli berasal dari pencarian informasi terkait pengetahuan dan manfaat produk, hal ini merupakan pertanda bahwa orang itu memiliki niat beli yang tinggi (Pertiwi dan Sukawati, 2017). Umumnya 
sebelum membeli suatu produk, konsumen akan mencari informasi mengenai produk tersebut, baik yang bersumber dari lingkungan sekitar maupun dari pengalam konsumen sendiri. Setelah memperoleh informasi, maka konsumen dapat melakukan penilaian terhadap produk yang akan dibeli, melakukan evaluasi, dan akhirnya mengambil keputusan apakah akan membeli atau tidak berdasarkan pertimbangan-pertimbangan sebelumnya.

Ambarawati (2015) menyatakan tahap awal dari timbulnya niat beli adalah konsumen akan berada pada proses pemikiran yang akan menghasilkan sebuah persepsi akan sebuah produk. Niat beli ini kemudian akan menjadi faktor pendorong yang memotivasi individu untuk memenuhi keinginannya membeli produk tersebut.

Niat beli akan mendorong terciptanya suatu motivasi yang terus tertanam dalam diri konsumen yang kemudian akan menjadi sebuah keinginan kuat, sehingga ketika konsumen memenuhi kebutuhannya, maka konsumen akan merealisasikan apa yang tertanam dalam dirinya tersebut. Tahap dimana konsumen bertindak sebelum keputusan membeli dilaksanakan disebut niat beli (Hidayati dkk., 2013). Pada penelitiannya, Hidayati dkk. (2013) menyatakan indikator yang membentuk niat beli diantaranya ketertarikan (interest), keinginan (desire), dan keyakinan (conviction).

Pengertian merek menurut Kotler \& Keller (2009: 241) mendefinisikan merek sebagai suatu nama, istilah, tanda, simbol, desain, atau kombinasi dari semuanya yang dimaksudkan untuk mengidentifikasikan suatu barang atau jasa dari satu penjual atau sekelompok penjual dan untuk membedakannya dari 
Ni Putu Ayu Kartika Kurnia Putri, Peran Citra Merek....

kompetitor lain. Menurut Kotler dan Keller (2009: 403) citra merek merupakan keyakinan serta pandangan yang dipercaya oleh konsumen sebagaimana yang diperlihatkan pada hubungan di dalam ingatan individu atau konsumen tersebut. Maghfiroh dkk. (2016) menyatakan pandangan dari konsumen dapat dipengaruhi oleh citra merek, dimana dewasa ini masyarakat sudah sangat selektif dalam menetukan merek mana yang sesuai dengan kebutuhan atau keinginan mereka. Hidayati dkk. (2013) menjelaskan citra merek menjadi salah satu faktor yang dapat membentuk cara pandang konsumen, dimana masyarakat akan memiliki kesan yang bagus mengenai merek tersebut, sehingga citra merek menjadi salah satu aset berharga perusahaan.

Secara umum citra merek dapat didefinisikan sebagai apa yang konsumen pikirkan dan rasakan ketika mendengar atau melihat nama suatu merek, semakin positif deskripsi konsumen tentang sebuah merek maka semakin kuat citra merek dari merek tersebut. Indikator dalam pengukuran citra merek dikemukakan oleh Shimp (2014: 40) serta Herliza dan Marheni (2016), diantaranya strengthness (kekuatan), uniqueness (keunikan), dan favourable. Indikator-indikator lain yang membentuk citra merek menurut Ruhamak dan Rahayu (2016) serta Hamidun dan Sanawiri (2018) adalah citra korporat, citra produk, dan citra pemakai.

Kotler dan Keller (2009 : 174) menjelaskan salah satu bagian dari bauran komunikasi pemasaran adalah komunikasi dari mulut ke mulut. Komunikasi dari mulut ke mulut ini dapat dilakukan secara tertulis, lisan, maupun secara elektronik antar individu di dalam masyarakat yang berkaitan dengan pengalaman mereka terhadap sebuah produk maupun jasa. Word of Mouth (WOM) mengalami 
perkembangan menjadi electronic word of mouth (e-WOM) sebagai dampak semakin berkembangnya teknologi. Komunikasi e-WOM melalui media elektronik maupun media sosial membantu konsumen memperoleh informasi lebih banyak melalui orang-orang yang tidak hanya ada disekitar konsumen namun orang-orang yang berada di wilayah berbeda dan sudah memiliki pengalaman menggunakan jasa atau membeli produk tersebut.

Informasi yang terkumpul melalui e-WOM dapat dijadikan dasar pertimbangan sebelum konsumen melakukan pembelian. Abubakar et al. (2016) menjelaskan bahwa $e$-WOM adalah pernyataan baik atau buruk yang bersumber dari para konsumen yang telah melakukan pembelian lebih dulu terhadap produk atau jasa tertentu dan ditujukan untuk semua orang, memanfaatkan internet. $e$ WOM secara umum dapat diartikan sebagai bentuk komunikasi akibat adanya perkembangan teknologi, dimana e-WOM merupakan perkembangan dari $W O M$. Sa'ait et al. (2016) menyatakan e-WOM lebih dapat diandalkan karena orangorang yang menyebarkan informasi secara online tentang produk dengan memberikan pengalaman asli, dimana orang-orang tersebut tidak dibayar, dan tidak terikat pada merek tertentu.

Pada penelitiannya, Thurau et al. (2004) merefleksikan e-WOM menjadi 8 dimensi, yaitu platform asistance, venting negative feeling, concern for othér consumers, extraversion /positives self-enchancement, social benefits, economic incentive, helping the company, dan advice seeking. Indikator-indikator yang membentuk e-WOM menurut Humaira dan Wibowo (2016) diantaranya tie strength, homophily, trust, normative influence, dan informational influence 
Komunikasi e-WOM yang semakin baik dan kuat dengan informasi positif yang tersebar mengenai sebuah produk akan menghasilkan citra merek yang semakin bagus bagi konsumen. Penelitian Jalilvand and Samiei (2012) menunjukkan e-WOM memiliki pengaruh positif dan signifikan terhadap citra merek. Hasil penelitian yang sama juga didukung oleh penelitian dari Torlak et al. (2014); Charo et al. (2015); Jafari et al. (2015); Elseidi and El-Baz (2016); Luong et al. (2017); Tariq et al. (2017); Abubakar et al. (2017); Khan and Ali (2017). Anggitasari dan Wijaya (2016) dalam penelitiannya mengemukakan e-WOM memiliki pengaruh positif dan signifikan pada citra merek, dimana $e$-WOM yang makin bagus mampu menciptakan citra merek yang makin meningkat bagi responden terhadap smartphone iPhone. Penelitian dengan hasil senada juga dikemukakan oleh penelitian dari Majid dan Rofiq (2014); Semuel dan Lianto (2014); Gadhafi (2015); Suwarduki dkk. (2016); Umamy dkk. (2016); Iswara dan Jatra (2017); Darmawan dan Nurcaya (2017); Eriza (2017); Adriyati dan Indriani (2017); Ardana dan Rastini (2018); Putra dan Pramudana (2018); Suyoga dan Santika (2018); Hamidun dan Sanawiri (2018). Berdasarkan dari hasil penelitian sebelumnya, maka pada penelitian ini dapat ditarik hipotesis sebagai berikut : $\mathrm{H}_{1}: e-W O M$ berpengaruh positif dan signifikan terhadap citra merek

Semakin baik review seseorang tentang produk berupa barang dan jasa di media sosial dapat menghasilkan niat beli yang semakin meningkat terhadap sebuah produk. e-WOM yang semakin baik akan mendorong konsumen untuk berniat melakukan pembelian. Penelitian Elseidi and El-Baz (2016) menjelaskan e-WOM memiliki pengaruh yang positif dan signifikan terhadap variabel niat beli. 
Hasil penelitian yang sama didukung penelitian dari Jalilvand and Samiei (2012); Setiawan (2014); Abubakar et al. (2017); Khan and Ali (2017). Gadhafi (2015) dalam penelitiannya mengemukakan e-WOM memiliki pengaruh positif dan signifikan pada niat beli. Penelitian dengan hasil senada juga dikemukakan oleh penelitian dari Semuel dan Lianto (2014); Anggitasari dan Wijaya (2016); Suwarduki dkk. (2016); Umamy dkk. (2016); Eriza (2017); Iswara dan Jatra (2017); Darmawan dan Nurcaya (2017); Adriyati dan Indriani (2017); Ardana dan Rastini (2018); Putra dan Pramudana (2018); Suyoga dan Santika (2018); Hamidun dan Sanawiri (2018). Berdasarkan dari hasil penelitian sebelumnya, maka pada penelitian ini dapat ditarik hipotesis sebagai berikut :

$\mathrm{H}_{2}: e-W O M$ berpengaruh positif dan signifikan terhadap niat beli.

Citra merek yang baik dari suatu produk berupa barang maka niat beli konsumen akan semakin tinggi. Penelitian yang dilakukan oleh Torlak et al. (2014) menunjukkan bahwa citra merek memiliki pengaruh positif dan signifikan terhadap niat beli. Hasil penelitian yang sama juga didukung oleh penelitian dari Jalilvand and Samiei (2012); Charo et al. (2015); Lien et al. (2015); Elseidi and El-Baz (2016); Abubakar et al. (2017); Pratama et al. (2017); Rehman and Ishac (2017).

Indra (2018) dalam penelitiannya mengemukakan citra merek memiliki pengaruh positif dan signifikan pada niat beli, dimana citra merek yang baik akan membuat calon pelanggan lebih percaya terhadap KPR bersubsidi dan dapat membentuk niat beli yang baik dan semakin tinggi. Penelitian dengan hasil senada juga dikemukakan oleh penelitian dari Majid dan Rofiq (2014); Semuel dan 
Lianto (2014); Anggitasari dan Wijaya (2016); Ruhamak dan Rahayu (2016); Suwarduki dkk. (2016); Umamy dkk. (2016); Moksaoka dan Rahyuda (2016); Randi dan Heryanto (2016); Adriyati dan Indriani (2017); Eriza (2017); Iswara dan Jatra (2017); Darmawan dan Nurcaya (2017); Pertiwi dan Sukawati (2017); Ardana dan Rastini (2018); Putra dan Pramudana (2018); Suyoga dan Santika (2018); Hamidun dan Sanawiri (2018). Berdasarkan pada penelitian di atas maka dapat ditarik hipotesis sebagai berikut :

$\mathrm{H}_{3}$ : Citra merek berpengaruh positif dan signifikan terhadap niat beli

Penelitian yang dilakukan oleh Khan and Ali (2017) menjelaskan citra merek memediasi pengaruh $e-W O M$ terhadap niat beli pada industri alas kaki di Pakistan, hal tersebut dikarenakan semakin baik e-WOM yang didapatkan oleh konsumen maka citra merek yang timbul dalam benak konsumen juga akan semakin baik sehingga akhirnya dapat mempengaruhi perilaku pembelian konsumen pada produk tersebut. Jalilvand and Samiei (2012) setuju bahwa $e$ WOM adalah salah satu faktor paling efektif yang mempengaruhi citra merek. Citra merek merupakan pandangan mengenai suatu merek sebagaimana yang tergambar oleh asosiasi merek yang ada pada ingatan konsumen. Studi empiris menunjukkan bahwa e-WOM mempunyai efek yang besar pada citra merek dan secara tidak langsung mengarah pada niat untuk membeli, khususnya di industri otomotif di Iran (Jalilvand and Samiei, 2012). Hasil penelitian Iswara dan Jatra (2017) menunjukkan bahwa citra merek cukup menentukan efektivitas dari pengaruh $e-W O M$ terhadap niat beli pada produk smartphone Samsung. Darmawan dan Nurcaya (2018) dalam penelitiannya mengemukakan bahwa citra 
merek mempunyai peran dalam memediasi pengaruh $e$-WOM terhadap niat beli produk iPhone. Penelitian lain menunjukkan citra merek mampu memediasi pengaruh e-WOM pada niat beli produk sepeda motor Yamaha Aerox di Kota Denpasar (Putra dan Pramudana, 2018). Variabel citra merek mampu memediasi pengaruh variabel e-WOM terhadap niat beli pada produk Richeese Factory yang ada di Kota Denpasar. Hasil penelitian tersebut menjelaskan e-WOM yang dilakukan konsumen memiliki dampak pada citra merek, oleh sebab itu mampu menciptakan niat beli pada diri konsumen (Suyoga dan Santika, 2018). Berdasarkan dari hasil penelitian sebelumnya, maka pada penelitian ini dapat ditarik hipotesis sebagai berikut :

$\mathrm{H}_{4}$ : Citra merek berperan dalam memediasi $e-W O M$ dengan niat beli

\section{METODE PENELITIAN}

Pendekatan yang digunakan dalam penelitian ini adalah pendekatan kuantitatif yang memiliki bentuk asosiatif dengan tujuuan melihat pengaruh $e$ $W O M$ terhadap citra merek, $e-W O M$ terhadap niat beli, dan citra merek terhadap niat beli, serta peran citra merek dalam memediasi hubungan $e-W O M$ terhadap niat beli. Metode pengumpulan data yang digunakan dalam penelitian ini adalah metode kuesioner dengan skala Likert. Terdapat tiga variabel dalam penelitian ini yaitu variabel bebas e-WOM $(\mathrm{X})$, variabel terikat niat beli $\left(\mathrm{Y}_{2}\right)$, dan variabel mediasi citra merek $\left(\mathrm{Y}_{1}\right)$.

Populasi yang digunakan pada penelitian ini adalah masyarakat Kota Denpasar yang jumlahnya tidak dapat diidentifikasi. Indikator yang digunakan berjumlah 11 indikator. Berdasarkan estimasi menggunakan jumlah parameter 
yang digunakan maka ukuran sampel yang diperoleh yaitu 55-110 rosponden. Jumlah sampel responden yang akan diuji pada penelitian ini sebanyak 110 responden. Metode penentuan sampel yang digunakan yaitu metode non probability sampling dengan teknik pengambilan sampel yaitu purposive sampling, dimana sampel ditentukan dengan pertimbanagn tertentu. Kriteria sampel pada penelitian ini adalah (1) berdomisili di Kota Denpasar, (2) sudah menamatkan pendidikan SMA/Sederajat, (3) mengetahui maskapai penerbangan AirAsia melalui media sosial, dan (4) belum pernah menggunakan jasa maskapai penerbangan AirAsia.

Teknik analisis yang digunakan yaitu analisis jalur (path analysis), uji sobel, dan uji VAF. Analisis jalur dalam penelitian ini berfungsi untuk melakukan analisis terhadap hubungan antar variabel yang bertujuan untuk mengetahui pengaruh langsung maupun tidak langsung variabel eksogen terhadap variabel endogen. Uji sobel berfungsi untuk menguji seberapa besar kekuatan dari pengaruh tidak langsung variabel $e-W O M(\mathrm{X})$ terhadap variabel niat beli $\left(\mathrm{Y}_{2}\right)$ melalui citra merek $\left(\mathrm{Y}_{1}\right)$. Uji VAF digunakan untuk menguji mediasi variabel citra merek $\left(\mathrm{Y}_{1}\right)$ pada pengaruh $e-\operatorname{WOM}(\mathrm{X})$ terhadap niat beli $\left(\mathrm{Y}_{2}\right)$.

\section{HASIL DAN PEMBAHASAN}

Berdasarkan penggolongan menurut jenis kelamin dalam penelitian ini hasilnya didominasi perempuan sebanyak 82 orang dengan persentase sebesar $74,5 \%$ dibandingkan dengan responden yang berjenis kelamin laki-laki sebanyak 28 orang dengan persentasi sebesar 25,5\%. Berdasarkan karakteristik usia, responden dengan usia 18-23 tahun memiliki jumlah responden terbanyak yaitu 
sebanyak 72 orang dengan persentase $65,4 \%$. Berdasarkan klasifikasi pendidikan terakhir, sebagian besar responden memiliki pendidikan terakhir SMA/Sederajat, yaitu sebanyak 86 orang dengan persentasi 78,2\%. Berdasarkan klasifikasi pekerjaan, sebagian besar responden memiliki pekerjaan sebagai mahasiswa/i, yaitu sebanyak 84 orang dengan persentase sebesar 76,4\%. Berdasarkan klasifikasi pendapatan perbulan, lebih didominasi oleh responden dengan tingkat pendapatan Rp. 1.000.000- Rp. 2.999.999, yaitu sebanyak 55 orang dengan persentasi sebesar $50.0 \%$ yang termasuk tingkat pendapatan perbulan menengah kebawah.

Hasil perhitungan koefisien jalur ditunjukkan pada Tabel 1. dan Tabel 2.

Tabel 1.

Hasil Analisis Jalur Sub-struktural 1

\begin{tabular}{llccc}
\hline Variabel & Standardized Coefficients & Std. Error & t hitung & Sig. $\mathrm{t}$ \\
\hline (Constant) & & 0,599 & 7,904 & 0,000 \\
e-WOM $(\mathrm{X})$ & 0,740 & 0,034 & 11,443 & 0,000 \\
R Square & 0,548 & & & \\
F Statistik & 130,941 & & & \\
Sig. F & 0,000 & & & \\
\hline Sumber: Data primer diolah, 2018 &
\end{tabular}

Persamaan struktural yang dapat disusun berdasarkan data pada Tabel 1 yaitu:

$$
\begin{aligned}
& \mathrm{Y}_{1}=\beta_{1} \mathrm{X}+\mathrm{e}_{1} \\
& \mathrm{Y}_{1}=0,740 \mathrm{X}
\end{aligned}
$$

Tabel 2.

Hasil Analisis Jalur Sub-struktural 2

\begin{tabular}{lcccc}
\hline Variabel & $\begin{array}{l}\text { Standardized } \\
\text { Coefficients }\end{array}$ & Std. Error & t hitung & Sig. t \\
\hline (Constant) & & 0,721 & 1,634 & 0,105 \\
$e-W O M(\mathrm{X})$ & 0,219 & 0,048 & 2,609 & 0,010 \\
Citra Merek $\left(\mathrm{Y}_{1}\right)$ & 0,636 & 0,092 & 7,581 & 0,000 \\
R Square & 0,659 & & & \\
F Statistik & 103,510 & & & \\
Sig. F & 0,000 & & & \\
\hline Sumber: & Data primer diolah 2018 & &
\end{tabular}

Sumber: Data primer diolah, 2018 
Persamaan struktural yang dapat disusun berdasarkan data pada Tabel 2 yaitu:

$$
\begin{aligned}
& \mathrm{Y}_{2}=\beta_{2} \mathrm{X}+\beta_{3} \mathrm{Y}_{1}+\mathrm{e}_{2} \ldots \ldots \\
& \mathrm{Y}_{2}=0,219 \mathrm{X}+0,636 \mathrm{Y}_{1}
\end{aligned}
$$

Berdasarkan model sub-struktural 1 dan model sub-struktural 2, maka diagram jalur akhir dapat disusun. Sebelum diagram jalur akhir disusun, nilai standar error akan dihitung terlebih dahulu, yaitu:

$$
\begin{aligned}
& \mathrm{e}=\sqrt{1-R^{2}} \ldots \ldots \ldots \ldots \ldots \ldots \ldots \ldots \ldots \ldots \ldots \ldots \ldots \ldots \ldots \ldots \ldots \\
& \mathrm{e}_{1}=\sqrt{1-R 1^{2}}=\sqrt{1-0,548}=0,672 \\
& \mathrm{e}_{2}=\sqrt{1-R 2^{2}}=\sqrt{1-0,659}=0,584
\end{aligned}
$$

Berdasarkan perhitungan pengaruh error (e), didapatkan hasil pengaruh error $\left(\mathrm{e}_{1}\right)$ dengan nilai 0,672 dan pengaruh error $\left(\mathrm{e}_{2}\right)$ dengan nilai 0,584.

Hasil dari koefisien determinasi total yaitu:

$$
\begin{aligned}
\mathrm{R}^{2} \mathrm{~m} & =1-\left(\mathrm{e}_{1}\right)^{2}\left(\mathrm{e}_{2}\right)^{2} \ldots \ldots \ldots \ldots \\
& =1-(0,672)^{2}(0,584)^{2} \\
& =1-(0,452)(0,341) \\
& =1-0,154 \\
& =0,846
\end{aligned}
$$

Determinasi total memiliki nilai 0,846 yang bermakna 84,6 persen variasi niat beli dipengaruhi oleh variasi $e-W O M$ serta variasi citra merek dan sisanya sebesar 15,4 persen dijelaskan oleh faktor lain.

Pengaruh e-WOM terhadap citra merek memperoleh Sig t dengan nilai 0,000 dan koefisien beta dengan nilai 0,740 . Sig. t $0.000 \leq 0,05$ menandakan bahwa $\mathrm{H}_{0}$ ditolak dan $\mathrm{H}_{1}$ diterima, sehingga dapat diinterpretasikan e-WOM memiliki pengaruh positif dan signifikan terhadap citra merek. 
Pengaruh e-WOM terhadap niat beli memperoleh Sig t dengan nilai 0,000 dan koefisien beta dengan nilai 0,219. Sig. t $0,010 \leq 0,05$ menandakan bahwa $\mathrm{H}_{0}$ ditolak dan $\mathrm{H}_{1}$ diterima, sehingga dapat diinterpretasikan e-WOM memiliki pengaruh positif dan signifikan terhadap niat beli.

Pengaruh citra merek terhadap niat beli memperoleh Sig t dengan nilai 0,000 dan koefisien beta dengan nilai 0,636 . Sig. t $0,000 \leq 0,05$ menandakan bahwa $\mathrm{H}_{0}$ ditolak dan $\mathrm{H}_{1}$ diterima, sehingga dapat diinterpretasikan citra merek memiliki pengaruh positif dan signifikan terhadap niat beli.

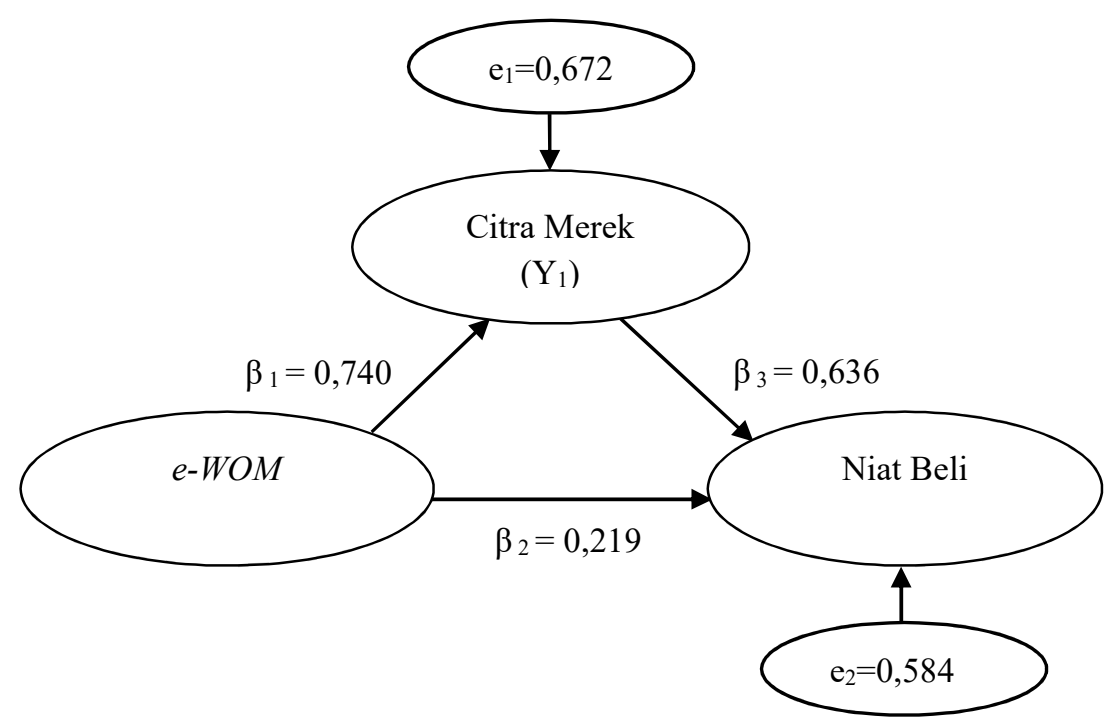

Gambar 1. Validasi Model Diagram Jalur Akhir Sumber: Data primer diolah, 2018

Pengaruh langsung, pengaruh tidak langsung, dan pengaruh total yang didasarkan pada Gambar 1, dapat dilihat pada Tabel 3.

Uji sobel dirumuskan menggunakan persamaan di bawah. Apabila nilai kalkulasi Z lebih besar dari 1,96 (tingkat kepercayaan 95 persen), maka variabel mediator dikatakan signifikan memediasi hubungan antara variabel endogen dengan variabel eksogen. 
Tabel 3

Pengaruh Langsung, Pengaruh Tidak Langsung, serta Pengaruh Total $e$ $\operatorname{WOM}(\mathrm{X})$, Citra Merek (Y $\left.\mathbf{Y}_{1}\right)$, dan Niat Beli $\left(\mathrm{Y}_{2}\right)$

\begin{tabular}{|c|c|c|c|}
\hline $\begin{array}{c}\text { Pengaruh } \\
\text { Variabel }\end{array}$ & $\begin{array}{l}\text { Pengaruh } \\
\text { Langsung }\end{array}$ & $\begin{array}{l}\text { Pengaruh Tidak Langsung Citra } \\
\operatorname{Merek}\left(\mathrm{Y}_{1}\right)=\left(\beta_{1} \times \beta_{3}\right)\end{array}$ & Pengaruh Total \\
\hline $\mathrm{X} \rightarrow \mathrm{Y}_{1}$ & 0,740 & - & 0,740 \\
\hline $\mathrm{X} \rightarrow \mathrm{Y}_{2}$ & 0,219 & 0,471 & 0,690 \\
\hline $\mathrm{Y}_{1} \longrightarrow \mathrm{Y}_{2}$ & 0,636 & - & 0,636 \\
\hline
\end{tabular}

$\mathrm{Sab}=\sqrt{\mathrm{a}^{2} \mathrm{Sb}^{2}+\mathrm{b}^{2} \mathrm{Sa}^{2}+\mathrm{Sa}^{2} \mathrm{Sb}^{2}}$

Keterangan:

$$
\begin{aligned}
& \mathrm{a}=0,384 \\
& \mathrm{Sa}=0,034 \\
& \mathrm{~b}=0,699 \\
& \mathrm{Sb}=0,092
\end{aligned}
$$

$$
\begin{aligned}
\mathrm{Sab} & =\sqrt{0,384^{2} 0,092^{2}+0,699^{2} 0,034^{2}+0,034^{2} 0,092^{2}} \\
& =\sqrt{0,00056+0,00125+0,00021} \\
& =\sqrt{0,00202} \\
& =0,045 \\
\mathrm{Z} \quad & \frac{a b}{S a b} \ldots \ldots \ldots \ldots \ldots \ldots \ldots \ldots \ldots \ldots \ldots \ldots \ldots \ldots \ldots \ldots \ldots \ldots \ldots \\
& =\frac{0,268}{0,045} \\
& =5,96
\end{aligned}
$$

Berdasarkan hasil uji Sobel dalam penelitian ini menunjukkan bahwa hasil tabulasi $Z=5,96>1,96$ yang berarti variabel mediasi yakni citra merek dinilai secara signifikansi mampu memediasi pengaruh e-WOM terhadap niat beli produk jasa maskapai penerbangan AirAsia di Kota Denpasar.

Variance Accounted For (VAF) dihitung menggunakan rumus sebagai berikut:

$$
\begin{aligned}
\mathrm{VAF} & =\frac{b \times c}{a+(b \times c)} \ldots \ldots \ldots \ldots \ldots \ldots \ldots \ldots \ldots \ldots \ldots \\
& =\frac{0,740 \times 0,636}{0,690+(0,740 \times 0,636)} \\
& =\frac{0,471}{1,161} \\
& =0,406 \text { atau } 40,6 \text { persen. }
\end{aligned}
$$


Nilai VAF sebesar 40,6 persen (lebih dari 20 persen), maka dapat dijelaskan bahwa ada efek mediasi. Dengan demikian, maka hipotesis yang menyatakan bahwa citra merek memediasi pengaruh $e-W O M$ terhadap niat beli dapat diterima.

Hipotesis pertama bertujuan untuk mengetahui pengaruh $e$-WOM terhadap citra merek. Berdasarkan hasil olah data diperoleh nilai koefisien beta positif sebesar 0,740 dengan tingkat signifikansi sebesar 0,000 (kurang dari 0,05) yang artinya $\mathrm{H}_{1}$ diterima. Hal ini mengindikasikan bahwa variabel e-WOM secara positif dan signifikan berpengaruh terhadap variabel citra merek. Hasil tersebut bermakna bahwa e-WOM yang makin bagus akan menyebabkan citra merek maskapai penerbangan AirAsia juga semakin bagus pada benak konsumen. Hasil penelitian yang sama juga ditunjukkan oleh peneliti-peneliti lainnya yaitu Jalilvand and Samiei (2012); Torlak et al. (2014); Charo et al. (2015); Jafari et al. (2015); Elseidi and El-Baz (2016); Luong et al. (2017); Tariq et al. (2017); Abubakar et al. (2017); Khan and Ali (2017); Majid dan Rofiq (2014); Semuel dan Lianto (2014); Gadhafi (2015); Suwarduki dkk. (2016); Umamy dkk. (2016); Iswara dan Jatra (2017); Darmawan dan Nurcaya (2017); Eriza (2017); Adriyati dan Indriani (2017); Ardana dan Rastini (2018); Putra dan Pramudana (2018); Suyoga dan Santika (2018); Hamidun dan Sanawiri (2018) yang menunjukkan hasil positif dan signifikan antara pengaruh e-WOM terhadap citra merek.

Hipotesis kedua bertujuan untuk mengetahui pengaruh e-WOM terhadap niat beli. Hasil penelitian dari olahan data menunjukkan nilai koefisien beta positif sebesar 0,219 dan memiliki signifikansi 0,010 (0,010 lebih kecil dari 0,05) sehingga $\mathrm{H}_{1}$ dapat diterima. Hasil ini mengindikasikan variabel e-WOM secara 
Ni Putu Ayu Kartika Kurnia Putri, Peran Citra Merek....

positif serta signifikan memiliki pengaruh terhadap variabel niat beli. Hasil ini berarti bahwa semakin baik e-WOM yang diterima, maka akan semakin meningkat pula niat beli konsumen terhadap maskapai penerbangan AirAsia. Hasil penelitian ini didukung beberapa penelitian sebelumnya yang telah dilakukan oleh Elseidi and El-Baz (2016); Jalilvand and Samiei (2012); Setiawan (2014); Abubakar et al. (2017); Khan and Ali (2017); Gadhafi (2015); Semuel dan Lianto (2014); Anggitasari dan Wijaya (2016); Suwarduki dkk. (2016); Umamy dkk. (2016); Eriza (2017); Iswara dan Jatra (2017); Darmawan dan Nurcaya (2017); Adriyati dan Indriani (2017); Ardana dan Rastini (2018); Putra dan Pramudana (2018); Suyoga dan Santika (2018); Hamidun dan Sanawiri (2018) yang menunjukkan hasil positif dan signifikan antara pengaruh $e$-WOM terhadap niat beli.

Hipotesis ketiga bertujuan untuk menganalisis pengaruh citra merek terhadap niat beli. Berdasarkan hasil olah data diperoleh nilai koefisien beta positif sebesar 0,636 dan memiliki signifikansi sebesar $0,000(0,000$ lebih kecil dari 0,05$)$ yang artinya $\mathrm{H}_{1}$ dapat diterima. Hal ini mengindikasikan bahwa variabel citra merek secara positif dan signifikan berpengaruh terhadap variabel niat beli. Hasil ini memiliki interpretasi citra merek yang semakin baik tertanam pada konsumen, mampu meningkatkan niat beli konsumen terhadap maskapai penerbangan AirAsia. Hasil penelitian ini sesuai dengan hasil penelitianpenelitian lainnya, yaitu Torlak et al. (2014); Jalilvand and Samiei (2012); Charo et al. (2015); Lien et al. (2015); Elseidi and El-Baz (2016); Abubakar et al. (2017); Pratama et al. (2017); Rehman and Ishac (2017); Indra (2018); Majid dan 
Rofiq (2014); Semuel dan Lianto (2014); Anggitasari dan Wijaya (2016); Ruhamak dan Rahayu (2016); Suwarduki dkk. (2016); Umamy dkk. (2016); Moksaoka dan Rahyuda (2016); Randi dan Heryanto (2016); Adriyati dan Indriani (2017); Eriza (2017); Iswara dan Jatra (2017); Darmawan dan Nurcaya (2017); Pertiwi dan Sukawati (2017); Ardana dan Rastini (2018); Putra dan Pramudana (2018); Suyoga dan Santika (2018); Hamidun dan Sanawiri (2018) yang menunjukkan hasil positif dan signifikan antara pengaruh citra merek terhadap niat beli.

Hipotesis keempat bertujuan untuk mengetahui pengaruh e-WOM terhadap niat beli menggunakan uji Sobel yang menunjukkan peran citra merek secara signifikan memediasi pengaruh $e$-WOM terhadap niat beli dengan hasil $\mathrm{Z}$ sebesar $5,96>1,96$. Berdasarkan hasil tersebut hipotesis keempat dalam penelitian ini diterima. Hal ini menunjukkan bahwa semakin baik e-WOM yang diterima oleh konsumen, maka citra merek yang terbentuk di benak konsumen akan semakin baik, secara tidak langsung citra merek yang baik tentunya akan mendorong niat beli konsumen yang tinggi terhadap maskapai penerbangan AirAsia. Berdasarkan perhitungan dari pengaruh e-WOM $(\mathrm{X})$ melalui citra merek $\left(\mathrm{Y}_{1}\right)$ terhadap niat beli $\left(\mathrm{Y}_{2}\right)$ diperoleh nilai VAF sebesar 40,6 persen, nilai ini berada diantara 20 persen hingga 80 persen, maka dapat dikategorikan sebagai pemediasi parsial (partial mediation). Hasil penelitian sejalan dengan penelitian sebelumnya yang dilakukan oleh Khan and Ali (2017); Jalilvand and Samiei (2012); Iswara dan Jatra (2017); Darmawan dan Nurcaya (2018); Putra dan Pramudana (2018); Suyoga dan 
Santika (2018); yang menunjukkan hasil bahwa citra merek dapat memediasi pengaruh $e-W O M$ terhadap niat beli.

\section{SIMPULAN DAN SARAN}

Simpulan dari penelitian ini yaitu, (1) $e-W O M$ berpengaruh positif dan signifikan terhadap citra merek. Hasil penelitian ini bermakna semakin baik $e$ WOM maka citra merek yang tercipta dari maskapai penerbangan AirAsia juga akan semakin baik. (2) $e$-WOM berpengaruh positif dan signifikan terhadap niat beli. Hasil penelitian ini bermakna semakin baik e-WOM yang terjadi maka rasa ingin tahu konsumen akan meningkat yang pada akhirnya mampu menimbulkan niat beli pada jasa maskapai penerbangan AirAsia seiring dengan berjalannya waktu. (3) Citra merek berpengaruh positif dan signifikan terhadap niat beli. Hasil ini berarti bahwa semakin baik citra merek yang tertanam di benak konsumen maka akan semakin baik pula niat beli pada jasa maskapai penerbangan AirAsia. (4) Citra merek mampu memediasi hubungan antara $e$-WOM terhadap niat beli. Hal ini berarti bahwa citra merek konsumen yang baik terhadap maskapai penerbangan AirAsia mampu memperkuat pengaruh e-WOM terhadap niat beli jasa maskapai penerbangan AirAsia di Kota Denpasar.

Beberapa keterbatasan penelitian ini adalah diantaranya, (1) ruang lingkup penelitian terbatas pada wilayah Kota Denpasar dengan jumlah sampel sebanyak 110 orang, sehingga hasil penelitian ini tidak dapat digeneralisasi dalam lingkup yang lebih luas. (2) Penelitian ini hanya dilakukan dalam titik waktu tertentu (cross section), sedangkan lingkungan setiap saat berubah (dinamis), sehingga penelitian ini penting untuk dilakukan kembali untuk peneliti selanjutnya. (3) 
Penelitian ini hanya meneliti pengaruh variabel $e$-WOM terhadap niat beli yang dimediasi oleh variabel citra merek, sedangkan masih terdapat banyak faktor yang mempengaruhi niat beli, misalnya kualitas produk, kualitas layanan, dan masih banyak lagi sehingga penelitian ini penting untuk dilakukan kembali. (4) Penelitian ini membahas mengenai niat beli konsumen pada jasa maskapai penerbangan AirAsia, sehingga penelitian selanjutnya diharapkan dapat mengembangkan bentuk penelitian yang membahas niat pembelian ulang dalam artian konsumen memang benar-benar melakukan pembelian terhadap jasa maskapai penerbangan AirAsia.

Saran untuk penelitian di masa yang akan datang perlu mempertimbangkan penggunaan variabel lain yang dapat mempengaruhi niat beli untuk produk jasa maskapai penerbangan AirAsia, misalnya saja seperti variabel perilaku konsumen lainnya, variabel demografi, variabel kualitas layanan, dan lain sebagainya sehingga mampu menganalisis secara lebih lanjut faktor - faktor yang memiliki pengaruh terhadap niat beli. Penelitian selanjutnya mengenai topik ini agar memperluas wilayah penelitian, dimana lokasi penelitian tidak hanya terfokus di Kota Denpasar namun di daerah lain juga.

\section{REFERENSI}

Abubakar, M., Ilkan, M., \& Sahin, P. (2016). eWOM, eReferral and Gender in the Virtual Community. Marketing Intelligence \& Planning. 34 (5), 692-710.

Adriyati, R., \& Indriani, F. (2017). Pengaruh Electronic Word of Mouth terhadap Citra Merek dan Minat Beli pada Produk Kosmetik Wardah. Diponogoro Journal Of Management. 6 (4), 1-14.

Ambarawati, M. (2015). Pengaruh Citra Merek terhadap Minat Beli. Jurnal Administrasi Bisnis (JAB), 25 (1), 40-55. 
Andriansyah. (2015). Manajemen Transportasi dalam Kajian dan Teori. Jakarta Pusat: Fakultas Ilmu sosial dan Ilmu Politik Universitas Prof. Dr. Moestopo Beragama.

Anggitasari, A. M. \& Wijaya, T. (2016). Pengaruh e-WOM terhadap Brand Image dan Brand Trust, serta Dampaknya pada Minat Beli Produk Smartphone Iphone (Studi pada Masyarakat di Yogyakarta). Jurnal Manajemen Bisnis Indonesia. 5 (3), 266-275.

Ardana, Y. A. \& Rastini, N. M. (2018) Peran Citra Merek Memediasi Pengaruh E-WOM terhadap Minat Beli Smartphone Samsung di Kota Denpasar. EJurnal Manajemen Unud, 7 (11), 5901 - 5929.

Azmarani, A. W. (2016). Analisis Kualitas Pelayanan Maskapai Penerbangan Low Cost Carrier (Studi Deskriptif Di PT. Citilink Indonesia Cabang Surabaya). Kebijakan dan Manajemen Publik, 4 (3), 56-70.

Charo, N., Sharma, P., Shaikh, S., Haseeb, A. and Sufya, M. (2015). Determining the Impact of E-WOM on Brand Image and Purchase Intention through Adoption of Online Opinions. International Journal of Humanities and Management Sciences (IJHMS), 3 (1), 41-46.

Darmawan, R. \& Nurcaya, I. N. (2018). Membangun Niat Beli Iphone Melalui EWOM dan Brand Image. E-Jurnal Manajemen Unud, 7 (9), 5168-5196.

Elseidi, R. I. \& El-Baz, D. (2016). Electronic Word of Mouth Effects on Consumers' Brand Attitudes, Brand Image and Purchase Intention: An Empirical Study in Egypt. The Business and Management Review, 7 (5), 514-523.

Eriza, Z. N. (2017). Peran Memediasi Citra Merek dan Persepsi Risiko pada Hubungan antara Electronic Word of Mouth (E-WOM) dan Minat Beli (Studi pada Konsumen Kosmetik E-Commerce di Solo Raya). Komuniti, 9 (1), 2549-5623.

Fahrian, F., Hasiolan, L. B., \& Haryono, A. T. (2015). Pengaruh Citra Merek, Lokasi, Kepercayaan dan Kualitas Pelayanan terhadap Minat Membeli BBM di SPBU Gasindo Mekar Putra Semarang. Journal of Management, 1 ( 1), $1-19$.

Hamidun, M. A., \& Sanawiri, B. (2018). Pengaruh Electronic Word of Mouth terhadap Purchase Intention melalui Brand Image (Studi pada Followers Akun Instagram @Ouvalresearch). Jurnal Administrasi Bisnis (JAB), 61-68. 
Herliza, R. dan Marheni E. S. (2016). Pengaruh Brand Image terhadap Kepuasan Pelanggan Studi pada Zara di Mall PVJ Bandung. Jurnal Manajemen Telkom University, 3 (2), 1949-1955.

Hidayati, T. A, Suharyono, \& Fanani, D. (2013). Pengaruh Citra Merek terhadap Minat Beli dan Keputusan Pembelian Konsumen. Jurnal Administrasi Bisnis. 2 (1), 162-171.

Humaira, A. \& Wibowo, L. A. (2016). Analisis Faktor Elektronik Word of Mouth (EWOM) dalam Mempengaruhi Keputusan Berkunjung Wisatawan. Tourism and Hospitality Essentials (THE) Journal, 6 (2), 1049-1060.

Indra, C. (2018). Pengaruh Word of Mouth terhadap Purchase Intention dengan Brand Image dan Perceived Service Quality sebagai Variabel Intervening pada Program KPR Bersubsidi di Surabaya. Jurnal Manajemen Pemasaran, $12(1), 1-9$.

Iswara, I. G. A. D., \& Jatra, I. M. (2017) Peran Brand Image dalam Memediasi Pengaruh Electronic Word of Mouth terhadap Purchase Intention (Studi Kasus pada Produk Smartphone Samsung di Kota Denpasar). E-Jurnal Manajemen Unud, 6 (8), 3991-4018.

Jafari, S. M. B., Karimi, A., Forouzandeh, M., \& Safahani, N. (2015). The Effect of Brand Commitment on e-WOM and Brand Image in the Mobile Market. Research Journal of Applied Science. 10 (10), 519-524.

Jalilvand, M. R. \& Samiei, N. (2012). The Effect of Electronik Word Of Mouth on Brand Image and Purchase Intention: An Empirical Study in the Automobile Industry in Iran. Marketing Intelligence \& Planning. 30, 460476.

Jotopurnomo, S., J., Laurensia, S., \& Semuel, H. (2015) Pengaruh Harga, Brand Image, dan Electronic Word of Mouth terhadap Minat Beli Reservasi Hotel secara Online. Jurnal Manajemen Pemasaran, 3 (4), 341-353.

Kadir, A. (2006). Transportasi: Peran dan Dampaknya dalam Pertumbuhan Ekonomi Nasional. Jurnal Perencanaan \& Pengembangan Wilayah Wahana Hijau, 1 (3), 123.

Khan, K. \& Ali, Mohammed. (2017). Impact of Electronic Word of Mouth on Consumer Purchase Intention in Footear Industry of Pakistan. An Open Access Journal, 6 (12), 52-63. 
Kotler, P. \& Keller, K. L. (2009). Manajemen Pemasaran (Jilid 1 Edisi ke 13), Jakarta: Erlangga.

Lien, C., Wen, M., Huang, L., \& Wu, K. (2015). Online Hotel Booking: The Effects of Brand Image, Price, Trust and Value on Purchase Intentions. Asia Pacific Management Review, 20 (4), 210-218.

Luong, D. B., Thi H. G. V., \& Khao H. L. (2017). The Impact of Electronic Word of Mouth on Brand Image and Buying Decision: an Empirical Study in Vietnam Tourism. International Journal of Research Studies. 6 (1), 53-63.

Maghfiroh, A., Arifin, Z., \& Sunarti. (2016). Pengaruh Citra Merek terhadap Minat Beli dan Keputusan Pembelian (Survei pada Mahasiswa Program Studi Administrasi Binis Tahun Angkatan 2013/2014 Fakultas Ilmu Adminisirasi Universitas Brawijaya Malang Pembeli Indosat Ooredoo). Jurnal Administrasi Bisnis. 40 (1), 132-140.

Mahendrayasa, A. C., Kumadji, Srikandi., \& Abdilah, Y. (2014). Pengaruh Word of Mouth terhadap Minat Beli serta Dampaknya pada Keputusan Pembelian (Survei pada Mahasiswa Pengguna Kartu Selular GSM "IMS" Angkatan 2011/2012 dan 2012/2013 Fakultas Ilmu/Adminitrasi Universitas Brawijaya Malang). Jurnal Administrasi Bisnis, 12 (1), 1-7.

Majalah Marketing GlobeAsia. (2018). AirAsia: Disruption for Future Growth. 22-25.

Majid, N. \& Rofiq, A. (2014). Analisis Pengaruh Electronic Word of Mouth terhadap Brand Image dan Dampaknya pada Minat Beli Smartphone Samsung di Kota Malang. Jurnal Ilmiah Mahasiswa FEB Universitas Brawijaya, 2 (2), 1-13.

Moksaoka, I. M. W. \& Rahyuda, I. K. (2016). Peran Brand Image dalam Memediesi Country of Origin terhadap Purchase Intention. E-Jurnal Manajamen Unud. 5 (3), 1960-1716.

Panggalih, R. G. dan Baridwan. (2013). Minat Individu Terhadap Penggunaan Internet Banking : Pendekatan Modified Theory of Planned Behavior. Jurnal Manajemen Pemasaran Universitas Brawijaya, 1 (2), 1-20.

Pertiwi, K. Y. \& Sukawati, T. G. R. (2017) Brand Image Memediasi WOM terhadap Niat Menggunakan Wedding Service di Cahya Dewi Beauty Salon Denpasar. E-Jurnal Manajemen Unud, 6 (5), 2609-2641. 
Prabhawedasattya, I.G.A.P.A \& Kerti Yasa, N. N. (2013). Pengaruh Ekuitas Merek terhadap Preferensi Merek dan Niat Beli Konsumen pada Produk iPhone di Kota Denpasar. Jurnal Manajemen Ekonomi. 2 (11), 1525-1551.

Pratama, I. G. B. A, Kerti Yasa, N. N., \& Nurcahya, N. (2018). The Role of Brand Image in Mediating the Influence of Sponsorship on the Intention to Purchase. Internarional Journal of Management and Commerce Innovation. 5 (2), 997-1003.

Putra, I. G. N. M. W. \& Pramudana, K. A. S. (2018). Peran Citra Merek dalam Memediasi Pengaruh E-WOM terhadap Niat Beli Motor Yamaha Aerox di Denpasar. E-Jurnal Manajemen Unud, 7 (9), 5108-5138.

Randi \& Heryanto, M. (2016). Pengaruh Citra Merek terhadap Minat Beli pada Makenen Fast Food Ayam Goreng (Studi pada Konsumen Texas Chicken Pekanbaru). Jurnal Online Mahasiswa Fakultas Ilmu Sosial dan Ilmu Poltik, $3(2), 1-9$.

Rehman, H. I. U. \& Ishaq, Z. (2017). The Impact of Brand Image on Purchase Intention: Moderating Role of Store Image in Pakistan's Retail Sector. The IUP Journal of Brand Management, 17 (3), 55-66.

Rismawan, I. M. A. \& Purnami, N. M. (2017). Peran Price Discount Memoderasi Pengaruh Product Knowledge dan Celebrity Endorse terhadap Purchase Intention. E-Jurnal Manajemen Unud, 6 (1), 264-288.

Rizan, M., Setyaningsih, R., \& Saidani, B. (2016). The Influence of Service Quality and Price Toward Trust and Its Impac on Customer Loyalty of Low Cost Carrier Indonesia. Jurnal Riset Manajemen Sains Indonesia (JRMSI), 7 (1), 176-196.

Rizki, Y. S. (2013). Peran Masakapai Penerbangan Berbiaya Murah/Low Cost Carrier (LCC) di Bandara Adisutjipto-Yogyakarta untuk Mendukung Peningkatan Jumlah Wisatawan Domestik. Jurnal Perhubungan Udara, 39 (2), 145-166.

Ruhamak, M. D. \& Rayahu, B. (2016). Pengaruh Word of Mouth terhadap Purchase Intention melalui Brand Image pada Lembaga Kursus Bahasa Inggris Dynamic English Course Pare. Jurnal Ekonomi Universitas Kadiri, 1 (2), 188-204.

Sa'ait, N., Kanyan, A., \& Nazrin, M. F. (2016). The Effect of E-WOM on Customer Purchase Intention. International Academic Research Journal of Social Science, 2 (1), 73-80. 
Semuel, H. \& Lianto, A. S. (2014). Analisis eWOM, Brand Image, Brand Trust, dan Minat Beli Produk Smartphone di Surabaya. Jurnal Manajemen Pemasaran, 8 (2), 47-54

Sekar, P. (2015). 5 Pelajaran yang Bisa Dipetik Dari PR AirAsia. Diunduh dari Portal Lengkap Dunia Marketing website https://marketing.co.id/5pelajaran-yang-bisa-dipetik-dari-pr-airasia/

Setiani, B. (2015). Prinsip-Prinsip Pokok Pengelolaan Jasa Transportasi Udara. Jurnal Ilmiah Widia, 3 (2), 103-109.

Setiawan, P. (2014). The Effect of e-WOM on Destination Image, Satisfaction and Loyalty. International Journal of Business and Management Invention, 3 (1), 22-29.

Shimp, T. A. (2014). Komunikasi Pemasaran Terpadu dalam Periklanan dan Promosi. Jakarta: Salemba Empat

Shulfi Ks, Z. \& Syahnur, S. (2017). Analisis Kausalitas Transportasi Udara dan Pertumbuhan Ekonomi di Indonesia. Jurnal Ilmiah Mahasiswa (JIM) Ekonomi Pembangunan Fakultas Ekonomi dan Bisnis Unsyiah, 2 (4), 626636.

Suprapti, N. W. S. (2010). Prilaku Konsumen, Pemahaman Dasar dan Aplikasinya Dalam Strategi Pemasaran. Bali : Udayana University Press.

Suwarduki, P. R., Yulianto, E., \& Mawardi, M. K. (2016). Pengaruh Electronic Word of Mouth terhadap Citra Destinasi serta Dampaknya pada Minat dan Keputusan Berkunjung (Survei pada Followers Aktif Akun Instagram Indtravel yang Telah Mengunjungi Destinasi Wisata di Indonesia). Jurnal Administrasi Bisnis (JAB), 37 (2), 1-10.

Suyoga, I. B. G. A, \& Santika I. W. (2018). Peran Brand Image dalam Memediasi Pengaruh Electronic Word of Mouth terhadap Niat Beli. E-Jurnal Manajemen Unud, 7 (6), 3230-3257.

Tariq, M., Abbas, T., Abrar, M., \& Iqbal, A. (2017). E-WOM and Brand Awareness Impact on Consumer Purchase Intention: Mediating Role of Brand Image. Pakistan Administrative Review, 1 (1), 84-102.

Thurau, T. H., Gwinner, K. P., Walsh, G. W., \& Gremler, D. D. (2004). Electronic Word of Mouth Via Consumer Opinion Platforms: What Motivates Consumersmajidto Articulate Themselves on the Internet? Journal of Interactive Marketing, 18 (1), 38-52. 
Top Brand Award. (2018). Diunduh dari Top Brand Award website:http://www.topbrand-award.com/

Torlak, O., Ozkara, B. Y., Tiltany, M. A., Cengiz, H., \& Dulger, M. F. (2014). The Effect of Electronic Word of Mouth on Brand Image and Purchase Intention: an Application Conceming Cell Phone Brands for Youth Consumers in Turkey. Journal of Marketing Development and Competitiveness, 8 (2), 61-68.

Umamy, C., Kumadji, S., \& Yulianto, E. (2016). Pengaruh Electronic Word of Mouth terhadap Brand Image serta Dampaknya pada Minat Beli (Survei pada Mahasiswa Universitas Brawijaya Malang Angkatan 2015/2016 Pengguna Smartphone). Jurnal Administrasi Bisnis (JAB), 33 (1), 114-119.

Undang-Undang Republik Indonesia Nomor 1 Tahun 2009 tentang Penerbangan. (2009). Indonesia. 